\title{
Systematic review of the complications of plate fixation of clavicle fractures
}

\author{
Frans-Jasper G. Wijdicks • Olivier A. J. Van der Meijden • \\ Peter J. Millett • Egbert J. M. M. Verleisdonk • \\ R. Marijn Houwert
}

Received: 15 August 2011/Published online: 10 January 2012

(C) The Author(s) 2012. This article is published with open access at Springerlink.com

\begin{abstract}
Background The number of displaced midshaft clavicle fractures treated surgically is increasing and plate fixation is often the treatment modality of choice. The study quality and scientific levels of evidence at which possible complications of this treatment are presented vary greatly in literature.

Purposes The purpose of this systematic review is to assess the prevalence of complications concerning plate fixation of dislocated midshaft clavicle fractures.

Methods A computer-based search was carried out using EMBASE and PUBMED/MEDLINE. Studies included for review reported complications after plate fixation alone or in comparison to either treatment with intramedullary pin fixation and/or nonoperative treatment. Two quality assessment tools were used to assess the methodological
\end{abstract}

F.-J. G. Wijdicks - E. J. M. M. Verleisdonk - R. M. Houwert Department of Surgery, Diakonessenhuis, Bosboomstraat 1, 3582 KE Utrecht, The Netherlands

e-mail: ejverleisdonk@diakhuis.nl

R. M. Houwert

e-mail: marijnhouwert@hotmail.com

F.-J. G. Wijdicks $(\bowtie)$

Griftstraat 34, 3572 GW Utrecht, The Netherlands

e-mail: fjgwijdicks@gmail.com

O. A. J. Van der Meijden · P. J. Millett

Steadman Philippon Research Institute, 181 W. Meadow Drive, Suite 1000, Vail, CO 81657, USA

e-mail: olivier@sprivail.org

P. J. Millett

The Steadman Clinic, 181 West Meadow Drive,

Suite 400, Vail, CO 81657, USA

e-mail: drmillett@thesteadmanclinic.com quality of the studies. Included studies were ranked according to their levels of evidence.

Results After study selection and reading of the full texts, 11 studies were eligible for final quality assessment. Nonunion and malunion rates were less than $10 \%$ in all analysed studies but one. The vast majority of complications seem to be implant related, with irritation or failure of the plate being consistently reported on in almost every study, on average ranging from 9 to $64 \%$.

Conclusion The quantity of relevant high evidence studies is low. With low nonunion and malunion rates, plate fixation can be a safe treatment option for acute dislocated midshaft clavicle fractures, but complications related to the implant material requiring a second operation are frequent. Future prospective trials are needed to analyse the influence of various plate types and plate position on implantrelated complications.

Keywords Review - Plate fixation - Midshaft dislocated clavicle fractures $\cdot$ Complications

\section{Introduction}

Clavicle fractures in adults occur quite frequently; approximately $5 \%$ of all fractures concern the clavicle. The vast majority of fractures, approximately $80 \%$, is located in the midshaft of the clavicle and half of these fractures are displaced [25, 27].

In the past, treatment of choice for most midshaft clavicle fractures was nonoperative with a sling or figureof-eight bandage [24, 30]. Reported nonunion rates following surgical fixation of clavicle fractures were initially higher than those reported following nonoperative treatment $[24,30]$. More recent studies, however, suggest 
higher complication and nonunion rates of up to $15 \%$ following nonoperative treatment, in particular for patients with displaced midshaft clavicle fractures (DMCF) [6, 12, $17,22,34,39]$. In addition, these patients are at high risk of residual pain, disappointing cosmesis and shoulder dysfunction [6, 12, 22, 39].

A regularly used surgical treatment option for DMCF is plate fixation. An advantage of plate fixation is the immediate stability it provides which enables early postoperative mobilization [13, 23, 24]. Several types of plates and fixation methods have been previously described; these include (precontoured) dynamic compression plates (DCP), tubular plates or reconstruction plates [13, 23]. Although high success rates of plate fixation of displaced clavicle fractures have been shown, reported complications of plate fixation include implant failure, (deep) infections, implant prominence, poor cosmesis, nonunions and refracture as a result of removal of the plate $[4,8,9]$. The study quality and scientific levels of evidence at which complications are presented, however, vary greatly in literature. Different reviews are performed on clavicle fractures, but none of these reviews specifically address the complications of plate fixation for dislocated midshaft clavicular fractures.

This systematic review aims at answering the following questions: (1) What is the incidence of minor and major complications after surgical plate fixation of acute DMCF?

(2) What is the value of reported complications in terms of the scientific level of evidence at which they are presented?

(3) What are the frequency and severity of the long-term consequences of major complications after plate fixation? (4) what conclusions may be drawn from these findings and how may it influence treatment of midshaft clavicle fractures?

\section{Methods}

\section{Search strategy}

On 4th April 2011, a computer-aided search using EMBASE and PUBMED/MEDLINE was conducted using the first two phases of the optimal search strategy from the Cochrane Handbook (http://www.cochrane-handbook.com). This strategy was combined with a subject specific search ("Appendix I"). Reference and citation tracking was used to complete the search database.

Inclusion criteria

Studies included for review reported complications after acute, displaced, midshaft clavicle fractures treated with plate fixation alone or in comparison to either treatment with intramedullary pin fixation and/or nonoperative treatment. Degree of fracture displacement had to be noted in the "Materials and methods" section for studies to be enrolled for further analysis. Studies in English, Dutch, German or French were assessed for inclusion. Case reports, biomechanical studies, papers describing a surgical technique and reviews were excluded from the database. Studies reporting on complications of the operative treatment of clavicle malunions, nonunions, open fractures, multiple fractures to the shoulder girdle, pathologic fractures, additional morbidity (i.e. floating shoulder) or fractures that had initial nonoperative treatment as starting point were also excluded.

\section{Selection of studies}

After the initial search strategy was performed, the remaining studies were screened for inclusion criteria based on their title/abstract by two researchers (FJGW, OAJvdM). Studies eligible for inclusion were additionally read completely for final inclusion. Finally, (prospective) trials without any notice of ethics committee consultation or approval were excluded from further assessment. Disagreement between the reviewers was resolved by discussion with another independent reviewer (RMH).

\section{Quality assessment}

Two quality assessment tools were used to assess the methodological quality of the final selection of studies. Assessment was performed without masking the source or authorship of trial reports. The two tools used were the level of evidence (LoE) rating according to the Oxford Centre of Evidence Based Medicine (http://www.cebm.net) and the modified version of the Cochrane Bone, Joint and Muscle Trauma Group's former quality assessment tool (QAT, http://www.cochrane-handbook.com). Studies were first labeled according to their LoE (Level I: high evidence, Level II: moderate evidence, Level III: low evidence, Level IV: very low evidence). Secondly, the QAT was used to assess the research quality into more detail. The QAT is a tool that scores an article on 11 items: 7 items on internal validity and 4 items on external validity. Disagreement between the reviewers about the quality assessment was again resolved by discussion with another independent reviewer $(\mathrm{RM})$.

Data extraction and analysis

Included studies were ranked according to their levels of evidence. The study characteristics, including design, type and position of plate used for fixation and follow-up time were also taken into account. 
Complications following the plate fixation of DMCF were identified and broken down into the following categories, if possible; bone-healing problems (nonunion and symptomatic malunion), infection (deep or wound), implant related problems (breakage, mechanical failure, irritation, angulation), plate debridement, removal or revision, neurovascular problems (transient or persistent brachial plexus symptoms, regional pain syndrome), refracture after plate removal and other complications. These categories were further subcategorized into two groups; major and minor complications. Major complications are characterized as a complication that needs another surgery to either remove or revise the plate as a result of the complication presented. Major complications are: nonunions, symptomatic malunion, deep infections, mechanical failure, irritation, breakage of the implant, angulation and refracture after plate removal. Minor complications are characterized as a complication that does not need another surgery and where a small intervention (i.e. oral antibiotics) may suffice. Minor complications are: wound infection and neurovascular problems. To avoid misinterpretation, the definitions of various complications stated in the reviewed studies were used in our analysis as much as possible.

\section{Results}

A total of 196 articles were identified, of which 27 were potentially relevant after screening the title and abstract and excluding doubles (Fig. 1). Full text screening resulted in 11 studies eligible for final quality assessment. There was no disagreement between the reviewers about the selection of the 11 final articles.

\section{Level of evidence}

Three studies were designed as randomized controlled trials and marked with the highest LoE (Table 1) [5, 10, 33]. All three studies report considerable wound infection rates (5-22\%) [5, 10, 33]. In addition, Shen et al. [33] report high nonunion rates of $13 \%$ in comparison to Ferran et al. [10] and the COTS [5], 0 and 3\%, respectively. They [5, $10]$, on the other hand, report significant rates of implantrelated problems requiring plate debridement, removal or even revision fixation, 10 and $53 \%$.

One study was graded LoE II, being designed as prospective cohort study [16] and reported complications were mainly implant related (Table 2). A total of four studies were designed as retrospective cohort studies and therefore labeled as LoE III [7, 21, 35, 36]. Again the main complications reported in these four studies were implantrelated problems (Table 3). Finally, three studies were assigned to LoE IV, all of them being retrospective case

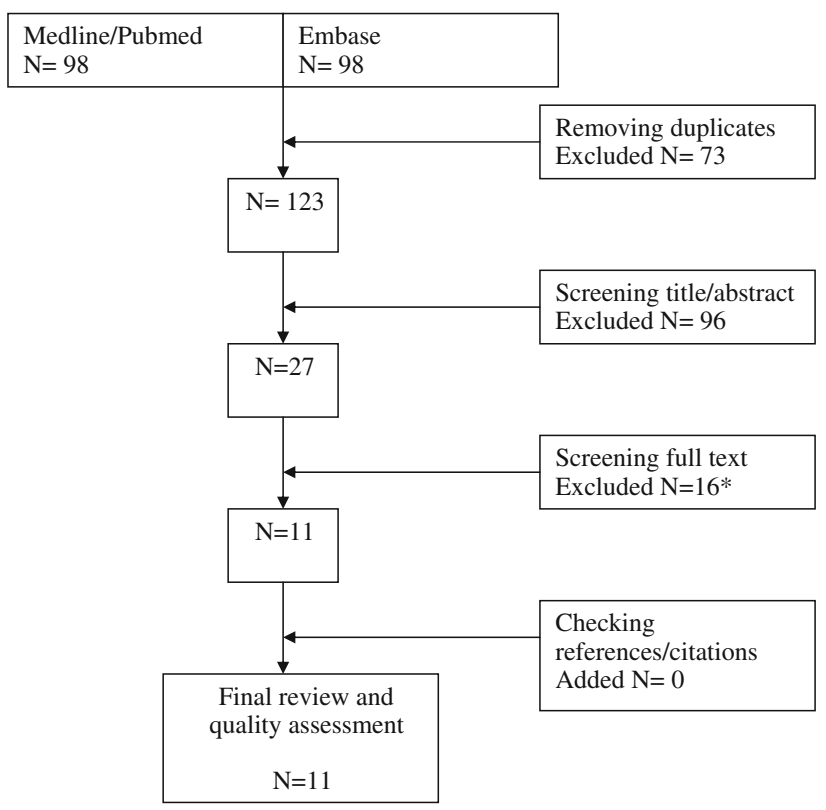

Fig. 1 Flowchart demonstrating the article search and appraisal process. Search was conducted on April 6th 2011. Asterisk excluded were one case report [29] and two studies in which there was no clear distinction made between postoperative complications after acute fractures and nonunions [9, 14]. Seven studies included complicated fractures and made no distinction with uncomplicated fractures when describing complications [3, 8, 15, 18-20, 32]. One study was a surgical technique paper [2], one study only reported outcomes and no complications [28], two studies had no clear definition of indication for surgery $[1,38]$ and, finally, two studies included different kinds of clavicle fractures (pathological, distal and nonunions) $[11,26]$

series $[4,31,37]$. The majority of complications again concerned the used implants (Table 4).

A total of 10 of the 11 assessed studies reported the usage of superior position for plate fixation $[4,5,7,10,16$, $21,3133,35,36]$. Anterior or anterior inferior plate positioning was analyzed in three studies [4, 16, 37]. The reconstruction plate and the low-contact dynamic compression plate (LCDCP) were the two most commonly used types for plate fixation.

\section{Quality assessment}

The majority of studies had well-defined in- and exclusion criteria, interventions and outcome measures. Adequate duration of follow-up was considered a minimum of 1 year which applied to most studies (Table 5). The study by the Canadian Orthopedic Trauma Society [5] was graded the strongest of selected studies and of highest scientific quality.

\section{Discussion}

The goal of this systematic review was to document the (prevalence of) complications after plate fixation of 
Table 1 Studies graded level of evidence I according to the Oxford Centre of Evidence Based Medicine (http://www.cebm.net)
$R C T$ randomized controlled trial, $L C D C P$ limited contact dynamic compression plate, $3 D$ 3-dimensional, $n / a$ not applicable (complication not mentioned in study)

${ }^{a}$ One plate was removed because the patient was a high level athlete

\begin{tabular}{|c|c|c|c|}
\hline & COTS [5] & $\begin{array}{l}\text { Ferran } \\
\text { et al. [10] }\end{array}$ & $\begin{array}{l}\text { Shen et al. } \\
\text { [33] }\end{array}$ \\
\hline \multicolumn{4}{|l|}{ Study characteristics } \\
\hline Design & $\begin{array}{l}\text { RCT; plating versus } \\
\text { nonoperative treatment }\end{array}$ & $\begin{array}{l}\text { RCT; plating } \\
\text { versus pin } \\
\text { fixation }\end{array}$ & $\begin{array}{l}\text { RCT; 'normal' } \\
\text { plating } \\
\text { versus 3D- } \\
\text { aided plating }\end{array}$ \\
\hline Number of plate fixations & $N=62$ & $N=15$ & $N=133$ \\
\hline Type of plate (times used) & $\begin{array}{l}\text { LCDCP (44), reconstruction } \\
\text { plate (15), precontoured } \\
\text { plate(4), } \\
\text { Other (4) }\end{array}$ & $\operatorname{LCDCP}(15)$ & $\begin{array}{l}\text { Reconstruction } \\
\text { plate; } \\
\text { 'Normal' } \\
\text { plating (66), } \\
\text { 3D-aided } \\
\text { plating 67) }\end{array}$ \\
\hline Plate positioning & Superior & Superior & Superior \\
\hline $\begin{array}{l}\text { Mean time to follow-up in } \\
\text { months (range) }\end{array}$ & 12 & $12(5-28)$ & 12 \\
\hline \multicolumn{4}{|l|}{ Complication rate } \\
\hline \multicolumn{4}{|l|}{ Bone-healing problem } \\
\hline Nonunion & $2(3 \%)$ & $0(0 \%)$ & $\begin{array}{l}8(12 \%) \text { versus } \\
1(1 \%)\end{array}$ \\
\hline (Symptomatic) Malunion & 0 & $\mathrm{n} / \mathrm{a}$ & \\
\hline \multicolumn{4}{|l|}{ Infection } \\
\hline Wound & $3(5 \%)$ & $3(20 \%)$ & $\begin{array}{l}12(19 \%) \\
\text { versus } \\
2(3 \%)\end{array}$ \\
\hline Deep & $\mathrm{n} / \mathrm{a}$ & $\mathrm{n} / \mathrm{a}$ & $\mathrm{n} / \mathrm{a}$ \\
\hline \multicolumn{4}{|l|}{ Implant breakage/failure/irritation } \\
\hline Irritation & $6(10 \%)$ & $3(20 \%)$ & $\mathrm{n} / \mathrm{a}$ \\
\hline Mechanical failure & $\mathrm{n} / \mathrm{a}$ & $\mathrm{n} / \mathrm{a}$ & $\mathrm{n} / \mathrm{a}$ \\
\hline $\begin{array}{l}\text { Plate debridement/removal/ } \\
\text { revision }\end{array}$ & $6(10 \%)$ & $8^{a}(53 \%)$ & $\mathrm{n} / \mathrm{a}$ \\
\hline \multicolumn{4}{|l|}{ Neurovascular problems } \\
\hline Brachial plexus symptoms & $8(13 \%)$ & $1(7 \%)$ & $\mathrm{n} / \mathrm{a}$ \\
\hline Regional pain syndrome & 0 & $1(7 \%)$ & $\mathrm{n} / \mathrm{a}$ \\
\hline Refracture after plate removal & 0 & $\mathrm{n} / \mathrm{a}$ & $\mathrm{n} / \mathrm{a}$ \\
\hline Other & $4(6 \%)$ & $\mathrm{n} / \mathrm{a}$ & 0 \\
\hline
\end{tabular}

DMCF. To obtain the best available evidence, relevant studies were scored on scientific methodology and the LoE they provide. We attempted to find an answer to the following questions; what is the incidence of minor and major complications after surgical plate fixation of acute DMCF? What is the value of reported complications in terms of the scientific level of evidence at which they are presented? What are the frequency and severity of the long-term consequences of major complications after plate fixation? And what conclusions may be drawn from these findings and how may it influence treatment of midshaft clavicle fractures? In response to our second question, we found that only three of the eligible studies provided the highest LoE [5, 10, 33]. Two of these studies included a sample- size calculation $[5,10]$. One study was a prospective cohort study but scored very well on quality assessment [16]. Based on their quality of methodology, we believe the studies by the COTS [5] and Kulshrestha et al. [16] to provide the best available evidence.

In search of an answer to our first question, we found nonunion rates were no higher than $10 \%$ in all analysed studies but one $[4,5,7,10,16,21,31,33,35,36]$. If reported on infection rates, both wound and deep infections were also below $10 \%$ in all but two studies $[4,5,7,10,21$, $31,33,35,36]$. The vast majority of these infections were wound infections, reportedly treated successfully with oral antibiotics. Neurovascular complications included brachial plexus symptoms and regional pain syndromes and ranged 
Table 2 Studies graded level of evidence I according to the Oxford Centre of Evidence Based Medicine (http://www.cebm.net)

n/a not applicable (complication not mentioned in study)

\begin{tabular}{|c|c|}
\hline & Kuhlshrestha et al. [16] \\
\hline \multicolumn{2}{|l|}{ Study characteristics } \\
\hline Design & $\begin{array}{l}\text { Prospective cohort; plating } \\
\text { versus nonoperative treatment }\end{array}$ \\
\hline Number of plate fixations & $N=45$ \\
\hline Type of plate (times used) & Reconstruction plate (45) \\
\hline Plate positioning & $\begin{array}{l}\text { Superior (15), anterior } \\
\text { inferior (30) }\end{array}$ \\
\hline $\begin{array}{l}\text { Mean time to follow-up } \\
\text { in months (range) }\end{array}$ & 12 \\
\hline \multicolumn{2}{|l|}{ Complication rate } \\
\hline \multicolumn{2}{|l|}{ Bone-healing problem } \\
\hline Nonunion & 0 \\
\hline (Symptomatic) Malunion & $2(4 \%)$ \\
\hline \multicolumn{2}{|l|}{ Infection } \\
\hline Wound & $\mathrm{n} / \mathrm{a}$ \\
\hline Deep & $\mathrm{n} / \mathrm{a}$ \\
\hline \multicolumn{2}{|l|}{ Implant breakage/failure/irritation } \\
\hline Irritation & $4(9 \%)$ \\
\hline Mechanical failure & $\mathrm{n} / \mathrm{a}$ \\
\hline Plate debridement/removal/revision & $4(9 \%)$ \\
\hline \multicolumn{2}{|l|}{ Neurovascular problems } \\
\hline Brachial plexus symptoms & $\mathrm{n} / \mathrm{a}$ \\
\hline Regional pain syndrome & $\mathrm{n} / \mathrm{a}$ \\
\hline Refracture after plate removal & 0 \\
\hline Other & $4(9 \%)$ \\
\hline
\end{tabular}

in prevalence from 0 to $38 \%$, all reportedly were transient $[4,5,7,10,31,35,37]$. Based on these figures, the incidence of minor complications (wound infections and neurovascular problems) is low.

Regardless of the LoE provided, the vast majority of complications seem to be implant related, with irritation or failure of the plate being consistently reported on in almost every study, on average ranging from 9 to $64 \%$ [5, $10,16,21,33,36]$.This is a point of concern, considering that, even in the better designed studies, a second operation with plate debridement, removal or revision was required at best in one out of every ten patients treated, in some studies even up to one out of every two patients $[4,5,10,16,21,31,35,36]$. There is a relatively small risk of refracture after plate removal, between 1 and 5\% $[4,31,36]$. However, it must be noted that only three of the 11 analyzed studies report on these numbers. In one study, two refractures after plate removal were reported [31]. This study compared LCDCP plates and reconstruction plates, and both refractures occurred after removal of LCDCP plates. Another study had a refracture after removal of a precountoured plate; the Locking Clavicle Plate [33]. The last refracture was reported after removal of an eight-screw dynamic compression plate [4]. The numbers presented above provide us with an answer to our third question. We conclude, based on the figures of plate debridement, removal or revision, that the incidence of major complications is high, ranging up to $64 \%$. Major complications require another surgery, but this surgery does treat the condition and complication and no long-term consequences are expected portraying low severity.

In light of our last question, this review points out that implant-related problems occur frequently. It is possible that the positioning of the plate anteriorly can decrease the number of complications. However, only one study mentioned that they felt that plate position initially influenced the outcome and complications of their treatment [16]. Additionally, plate type and pre-contouring to the anatomic shape of the clavicle may also have an influence. However, the current numbers available are too small and study designs to different to make any assumptions.

Although not optimal with regards to methodological qualities, we included retrospective case series in our analysis. In some studies, the complications were well documented and the reported complication rates were too 
Table 3 Studies graded level of evidence III according to the Oxford Centre of Evidence Based Medicine (http://www.cebm.net)

\begin{tabular}{|c|c|c|c|}
\hline & Vanbeek et al. [36] & Cho et al. [7] & Liu et al. [21] \\
\hline \multicolumn{4}{|l|}{ Study characteristics } \\
\hline Design & $\begin{array}{l}\text { Retrospective cohort study; noncontoured } \\
\text { plating versus contoured plating }\end{array}$ & $\begin{array}{l}\text { Retrospective cohort study; } \\
\text { reconstruction plating versus } \\
\text { reconstruction locking plating }\end{array}$ & $\begin{array}{l}\text { Retrospective } \\
\text { cohort study; } \\
\text { plating versus } \\
\text { pin fixation }\end{array}$ \\
\hline Number of plate fixations & $N=42$ & $N=41$ & $N=59$ \\
\hline Type of plate (times used) & $\begin{array}{l}\text { Noncontoured (14); DCP (4), LCP (2), } \\
\text { LCDCP (4), reconstruction plate (4), } \\
\text { precontoured (28); locking } \\
\text { clavicle plate (28) }\end{array}$ & $\begin{array}{l}\text { Precontoured; reconstruction } \\
\text { plate (19), reconstruction } \\
\text { LCP (22) }\end{array}$ & $\begin{array}{l}\text { Reconstruction } \\
\text { LCP (59) }\end{array}$ \\
\hline Plate positioning & Superior & Superior & Superior \\
\hline Mean time to follow-up in months (range) & 12 & $13(7-35)$ versus $12(7-24)$ & 12 \\
\hline \multicolumn{4}{|l|}{ Complication rate } \\
\hline \multicolumn{4}{|l|}{ Bone-healing problem } \\
\hline Nonunion & 0 versus $1(4 \%)$ & 0 & $6(10 \%)$ \\
\hline (Symptomatic) Malunion & $\mathrm{n} / \mathrm{a}$ & 0 & $2(3 \%)$ \\
\hline \multicolumn{4}{|l|}{ Infection } \\
\hline Wound & 0 versus $1(4 \%)$ & 0 & $6(10 \%)$ \\
\hline Deep & $\mathrm{n} / \mathrm{a}$ & 0 & \\
\hline \multicolumn{4}{|l|}{ Implant breakage/failure/irritation } \\
\hline Irritation & $9(64 \%)^{\mathrm{a}}$ versus $9(32 \%)$ & 0 & $12(20 \%)$ \\
\hline Mechanical failure & $\mathrm{n} / \mathrm{a}$ & 0 & $4(8 \%)$ \\
\hline Plate debridement/removal/revision & $3(21 \%)$ versus $3(11 \%)$ & $\mathrm{n} / \mathrm{a}$ & $14(24 \%)$ \\
\hline \multicolumn{4}{|l|}{ Neurovascular problems } \\
\hline Brachial plexus symptoms & $\mathrm{n} / \mathrm{a}$ & $\mathrm{n} / \mathrm{a}$ & $\mathrm{n} / \mathrm{a}$ \\
\hline Regional pain syndrome & $\mathrm{n} / \mathrm{a}$ & $2(11 \%)$ versus $1(5 \%)$ & $\mathrm{n} / \mathrm{a}$ \\
\hline Refracture after plate removal & 0 versus $1(4 \%)$ & 0 & $\mathrm{n} / \mathrm{a}$ \\
\hline Other & 0 versus $2(7 \%)$ & $7(39 \%)$ versus $5(23 \%)$ & $\mathrm{n} / \mathrm{a}$ \\
\hline
\end{tabular}

Thyagarajan et al. [35]

Study characteristics

Design

Number of plate fixations

Type of plate (times used)

Plate positioning

Mean time to follow-up in months (range)

Complication rate

Bone-healing problem

Nonunion

(Symptomatic) Malunion

Infection

Wound

Deep

Implant breakage/failure/irritation

Irritation

Mechanical failure

Plate debridement/removal/revision

Neurovascular problems

Brachial plexus symptoms

Regional pain syndrome

Refracture after plate removal

Other
Retrospective cohort study;

plating versus pin fixation versus

nonoperative treatment

$N=16$

LCDCP (16)

Superior

$6(4-11)$

$1(6 \%)$

n/a

$1(6 \%)$

$1(6 \%)$

$2(13 \%)$

$\mathrm{n} / \mathrm{a}$

$2(13 \%)$

$4(25 \%)$

$6(38 \%)$

$\mathrm{n} / \mathrm{a}$

$1(6 \%)$

LCDCP limited contact dynamic compression plate, $n / a$ not applicable (complication not mentioned in study)

${ }^{a}$ Removed noncontoured plates included DCP (1), LCDCP (1) and reconstruction plate (1) 
Table 4 Studies graded level of evidence IV according to the Oxford Centre of Evidence Based Medicine (http://www.cebm.net)

\begin{tabular}{|c|c|c|c|}
\hline & Russo et al. [31] & Verborgt et al. [37] & Böstman et al. [4] \\
\hline \multicolumn{4}{|l|}{ Study characteristics } \\
\hline Design & Retrospective case series & Retrospective case series & Retrospective case series \\
\hline Number of plate fixations & $N=43$ & $N=39$ & $N=103$ \\
\hline Type of plate (times used) & Mennen-plate & $\begin{array}{l}\text { Precontoured; reconstruction } \\
\text { plate (?) LCDCP (?) }\end{array}$ & $\begin{array}{l}\text { DCP (57), reconstruction } \\
\text { plate }(46)\end{array}$ \\
\hline Plate positioning & Superior & Anterior & $\begin{array}{l}\text { Anterior (57) } \\
\text { Superior (46) }\end{array}$ \\
\hline Mean time to follow-up in months (range) & 12 & 3 & $23(6-53)$ \\
\hline \multicolumn{4}{|l|}{ Complication rate } \\
\hline \multicolumn{4}{|l|}{ Bone-healing problem } \\
\hline Nonunion & $2(5 \%)$ & $2(5 \%)$ & $3(3 \%)$ \\
\hline (Symptomatic) Malunion & $\mathrm{n} / \mathrm{a}$ & $\mathrm{n} / \mathrm{a}$ & $12(12 \%)$ \\
\hline \multicolumn{4}{|l|}{ Infection } \\
\hline Wound & 0 & $4(10 \%)$ & $3(3 \%)$ \\
\hline Deep & 0 & $3(8 \%)$ & $5(5 \%)$ \\
\hline \multicolumn{4}{|l|}{ Implant breakage/failure/irritation } \\
\hline Irritation & 0 & $\mathrm{n} / \mathrm{a}$ & $\mathrm{n} / \mathrm{a}$ \\
\hline Mechanical failure & 0 & $2(5 \%)$ & $16(16 \%)$ \\
\hline Plate debridement/removal/revision & $13^{\mathrm{a}}(30 \%)$ & $7(18 \%)$ & $14(14 \%)+54(52 \%)^{\mathrm{b}}$ \\
\hline \multicolumn{4}{|l|}{ Neurovascular problems } \\
\hline Brachial plexus symptoms & $10(23 \%)$ & $3(8 \%)$ & $2(2 \%)$ \\
\hline Regional pain syndrome & $\mathrm{n} / \mathrm{a}$ & $\mathrm{n} / \mathrm{a}$ & $\mathrm{n} / \mathrm{a}$ \\
\hline Refracture after plate removal & $\mathrm{n} / \mathrm{a}$ & $2(5 \%)^{\mathrm{c}}$ & $1(1 \%)$ \\
\hline Other & $2(5 \%)$ & $\mathrm{n} / \mathrm{a}$ & $\mathrm{n} / \mathrm{a}$ \\
\hline
\end{tabular}

LCDCP low contact dynamic compression plate, $D C P$ dynamic compression plate, $n / a$ not applicable (complication not mentioned in study)

a 11 patients requested removal of the plate for cosmetic reasons

b 54 patients underwent routine plate removal

${ }^{c}$ Refractures both after LCDCP plates

high to ignore. In particular in the studies by Russo et al. [31] and Bostman et al. [4], the authors gave detailed descriptions of encountered complications and the complication rates are high.

There are some limitations to this review. Proceedings from annual meetings (conferences) were not included in this review. Only PUBMED, EMBASE and the Cochrane databases were used for search. Therefore, some valuable information might be lost. However, at proceedings mostly interim analyses are reported and these results might differ from the final results. PUBMED and EMBASE are the largest medical databases. We thoroughly screened the studies and submitted them to a quality assessment which results in an evidence-based conclusion to what extend complications can be attributed to plate fixation. Because of the different study designs and characteristics, data could not be pooled and the data were summarized separately per study. We used the definitions of complications set forth in the analyzed studies to divide the complications into six main categories. However, different authors may have used different definitions for complications i.e. deep, superficial and wound infections. In the future, improvements can be made concerning definitions of complications. Actual complication rates might be higher than many authors report, based on distinctions made between minor and major complications and overlap in definitions (e.g. failure or infection may result in removal, debridement or revision).

Based on the overall low numbers of reported nonunion and symptomatic malunion, we conclude and answer our final question that plate fixation is a safe treatment option for DMCF. However, this review also points out that complications related to the implant material are frequent often requiring removal, revision or debridement of the plate. The quantity of high LoE studies to support this is limited. More prospective trials with well-defined complications as outcome measurements are needed to make more specific recommendations with regard to optimum plate position, the type of plate and possible postoperative complications regarding plate fixation for DMCF. 
Table 5 Quality assessment outcome of all analyzed studies according to the modified version of the Cochrane Bone, Joint and Muscle Trauma Group's former quality assessment tool (QAT, http://www.cochrane-handbook.com)

\begin{tabular}{|c|c|c|c|c|c|c|c|c|}
\hline Study & $\begin{array}{l}\text { Allocation } \\
\text { concealment }\end{array}$ & $\begin{array}{l}\text { Intention- to-treat } \\
\text { analysis }\end{array}$ & $\begin{array}{l}\text { Assessor } \\
\text { blinding }\end{array}$ & $\begin{array}{l}\text { Comparable baseline } \\
\text { characteristics }\end{array}$ & $\begin{array}{l}\text { Participant } \\
\text { blinding }\end{array}$ & $\begin{array}{l}\text { Treatment } \\
\text { provider blinding }\end{array}$ & $\begin{array}{l}\text { Care program } \\
\text { comparability }\end{array}$ & $\begin{array}{l}\text { Defined in - } \\
\text { and exclusion } \\
\text { criteria }\end{array}$ \\
\hline COTS et al. [29] & 2 & 2 & 0 & 2 & 0 & 0 & 2 & 2 \\
\hline Kulshrestva et al. [32] & 2 & 2 & 0 & 2 & 0 & 0 & 2 & 2 \\
\hline Ferran et al. [30] & 2 & 2 & 0 & 2 & 0 & 0 & 2 & 2 \\
\hline Shen et al. [31] & 2 & 2 & 2 & 2 & 2 & 0 & 0 & 1 \\
\hline Liu et al. [35] & 0 & 0 & 0 & 2 & 0 & 0 & 2 & 2 \\
\hline Cho et al. [34] & 0 & 0 & 0 & 1 & 0 & 0 & 2 & 1 \\
\hline Vanbeek et al. [33] & 0 & 0 & 0 & 2 & 0 & 0 & 2 & 2 \\
\hline Russo et al. [37] & 0 & 0 & 0 & 0 & 0 & 0 & 0 & 1 \\
\hline Bostman et al. [4] & 0 & 0 & 0 & 0 & 0 & 0 & 0 & 2 \\
\hline Thyagarajan et al. [36] & 0 & 0 & 0 & 2 & 0 & 0 & 0 & 2 \\
\hline Verborgt et al. [38] & 0 & 0 & 0 & 0 & 0 & 0 & 0 & 1 \\
\hline Study & & $\begin{array}{l}\text { I1-defined } \\
\text { rventions }\end{array}$ & $\begin{array}{l}\text { Well-def } \\
\text { outcome }\end{array}$ & $\begin{array}{l}\text { ned } \\
\text { measures }\end{array}$ & $\begin{array}{l}\text { Clinically usefu } \\
\text { diagnostic tests }\end{array}$ & $\begin{array}{l}\text { Adec } \\
\text { of fo }\end{array}$ & $\begin{array}{l}\text { uate duration } \\
\text { low-up }\end{array}$ & $\begin{array}{l}\text { QAT } \\
\text { Score }\end{array}$ \\
\hline COTS et al. [29] & 2 & & 2 & & 2 & 2 & & 18 \\
\hline Kulshrestva et al. [32] & 2 & & 2 & & 1 & 2 & & 17 \\
\hline Ferran et al. [30] & 2 & & 2 & & 1 & 2 & & 17 \\
\hline Shen et al. [31] & 2 & & 0 & & 0 & 2 & & 15 \\
\hline Liu et al. [35] & 2 & & 2 & & 2 & 2 & & 14 \\
\hline Cho et al. [34] & 2 & & 2 & & 2 & 1 & & 11 \\
\hline Vanbeek et al. [33] & 1 & & 2 & & 2 & 0 & & 11 \\
\hline Russo et al. [37] & 2 & & 2 & & 2 & 2 & & 9 \\
\hline Bostman et al. [4] & 2 & & 2 & & 1 & 1 & & 8 \\
\hline Thyagarajan et al. [36] & 1 & & 2 & & 0 & 0 & & 7 \\
\hline Verborgt et al. [38] & 1 & & 2 & & 1 & 2 & & 7 \\
\hline
\end{tabular}

Bold values indicate that the higher the value, the better methodological quality and least chance of bias, with a maximum score of 24

QAT quality assessment tool

Acknowledgments This work was not supported directly by an outside funding or grant. However, Dr. Millett is a consultant and receives payments from Arthrex and has stock options in Game Ready. In addition, Dr. Van der Meijden's research position was supported by Arthrex. This research was supported by The Steadman Philippon Research Institute which is a 501(c)3 nonprofit institution supported financially by private donations and corporate support from the following entities: Smith and Nephew Endoscopy, Arthrex, Arthrocare, Siemens, OrthoRehab, Ossur Americas and ConmedLinvatec.

Open Access This article is distributed under the terms of the Creative Commons Attribution Noncommercial License which permits any noncommercial use, distribution, and reproduction in any medium, provided the original author(s) and source are credited.

\section{Appendix I}

PUBMED/MEDLINE search string

$((((()(($ midshaft[Title/Abstract]) OR shaft[Title/Abstract]) OR shafts[Title/Abstract]) OR mid[Title/Abstract]) OR midclavicle[Title/Abstract]) OR middle[Title/Abstract]) OR mid-third[Title/Abstract]) OR diaphysis[Title/Abstract]) OR diaphyseal[Title/Abstract])

\section{AND}

$(((()($ clavicular[Title/Abstract]) OR clavicula[Title/ Abstract]) OR claviculae[Title/Abstract]) OR clavicle[Title/Abstract]) OR clavicles[Title/Abstract]) OR collarbone[Title/Abstract]) OR collarbones[Title/Abstract])

AND

(((()plating[Title/Abstract])OR plate[Title/Abstract]) OR plate-osteosynthesis[Title/Abstract]) OR plates[Title/ Abstract]) OR plate-fixation[Title/Abstract])

AND

(((fractures[Title/Abstract]) OR fracture[Title/Abstract]) OR fractured[Title/Abstract])

Embase search string

midshaft:ab,ti OR shaft:ab,ti OR shafts:ab,ti OR mid:ab,ti ORmidclavicle:ab,ti OR middle:ab,ti OR third:ab,ti OR diaphysis:ab,ti OR diaphysial;ab,ti AND (clavicular:ab,ti OR clavicula:ab,ti OR claviculae:ab,ti OR clavicle:ab,ti OR clavicles:ab,ti OR collarbone:ab,ti OR collarbones:ab,ti) AND (plating;ab,ti OR plate:ab,ti OR 
plate-osteosynthesis:ab,ti OR plates:ab,ti OR plate-fixation:ab,ti) AND (fractures:ab,ti OR fracture:ab,ti OR fractured:ab,ti) AND [embase]/lim

\section{References}

1. Ali Khan MA, Lucas HK (1978) Plating of fractures of the middle third of the clavicle. Injury 9(4):263-267

2. Altamimi SA, McKee MD, Canadian Orthopaedic Trauma Society (2008) Nonoperative treatment compared with plate fixation of displaced midshaft clavicular fractures. Surgical technique. J Bone Joint Surg Am 90(Suppl 2 Pt 1):1-8

3. Böhme J, Bonk A, Bacher GO, Wilharm A, Hoffmann R, Josten C (2011) Current treatment concepts for mid-shaft fractures of the clavicle-results of a prospective multicentre study. Z Orthop Unfall. 149(1):68-76

4. Bostman O, Manninen M, Pihlajamaki H (1997) Complications of plate fixation in fresh displaced midclavicular fractures. J Trauma 43:778-783

5. Canadian Orthopaedic Trauma Society (2007) Nonoperative treatment compared with plate fixation of displaced midshaft clavicular fractures. A multicenter, randomized clinical trial. J Bone Joint Surg Am 89(1):1-10

6. Chan KY, Jupiter JB, Leffert RD et al (1999) Clavicle malunion. J Shoulder Elbow Surg 8:287-290

7. Cho CH, Song KS, Min BW, Bae KC, Lee KJ (2010) Operative treatment of clavicle midshaft fractures: comparison between reconstruction plate and reconstruction locking compression plate. Clin Orthop Surg 2(3):154-159

8. Collinge C, Devinney S, Herscovici D (2006) Anterior-inferior plate fixation of middle-third fractures and nonunions of the clavicle. J Orthop Trauma 20:680-686

9. Coupe BD, Wimhurst JA, Indar R (2005) A new approach for plate fixation of midshaft clavicular fractures. Injury 36:1166-1171

10. Ferran NA, Hodgson P, Vannet N, Williams R, Evans RO (2010) Locked intramedullary fixation vs. plating for displaced and shortened mid-shaftclavicle fractures: a randomized clinical trial. J Shoulder Elbow Surg 19(6):783-789

11. Fuchs M, Losch A, Stürmer KM (2002) Surgical treatment of fractures of the clavicle-indication, surgical technique and results. Zentralbl Chir 127(6):479-484

12. Hill JM, Mcguire MH, Crosby LA (1997) Closed treatment of displaced middle-third fractures of the clavicle gives poor results. J Bone Joint Surg Br 79:537-539

13. Kabak S, Halici M, Tuncel M, Avsarogullari L, Karaoglu S (2004) Treatment of mid-clavicular nonunion: comparison of dynamic compression plating and low-contact dynamic compression plating techniques. J Shoulder Elbow Surg. 13:396-403

14. Kloen P, Werner CM, Stufkens SA, Helfet DL (2009) Anteroinferior plating of midshaft clavicle nonunions and fractures. Oper Orthop Traumatol. 21(2):170-179

15. Kulshrestha V (2008) Primary plating of displaced mid-shaft clavicular fractures. Med J Armed Forces India 64(3):208-211

16. Kulshrestha V, Roy T, Audige L (2011) Operative versus nonoperative management of displaced midshaft clavicle fractures: a prospective cohort study. J OrthopTrauma 25(1):31-38

17. Lazarides S, Zawropoulos G (2006) Conservative treatment of fractures at the middle third of the clavicle: the relevance of shortening and clinical outcome. J Shoulder Elbow Surg. 15:191-194

18. Lee YS, Lin CC, Huang CR, Chen CN, Liao WY (2007) Operative treatment of midclavicular fractures in 62 elderly patients: Knowles pin versus plate. Orthopedics 30(11):959-964
19. Lee YS, Huang HL, Lo TY, Hsieh YF, Huang CR (2008) Surgical treatment of midclavicular fractures: a prospective comparison of Knowles pinning and plate fixation. Int Orthop 32(4):541-545

20. Liu PC, Hsieh CH, Chen JC, Lu CC, Chuo CY, Chien SH (2008) Infection after surgical reconstruction of a clavicle fracture using a reconstruction plate: a report of seven cases. Kaohsiung J Med Sci 24(1):45-49

21. Liu HH, Chang $\mathrm{CH}$, Chia WT, Chen CH, Tarng YW, Wong CY (2010) Comparison of plates versus intramedullary nails for fixation of displaced midshaft clavicular fractures. J Trauma 69(6):E82-E87

22. McKee MD, Wild LM, Schemitsch EH (2003) Midshaft malunions of the clavicle. J Bone Joint Surg Am 85-A:790-797

23. Mullaji AB, Jupiter JB (1994) Low-contact dynamic compression plating of the clavicle. Injury. 25:41-45

24. Neer CSII (1960) Nonunion of the clavicle. JAMA 172: 1006-1011

25. Nordqvist A, Petersson C (1994) The incidence of fractures of the clavicle. Clin Orthop Relat Res 300:127-132

26. Poigenfürst J, Reiler T, Fischer W (1988) Plating of fresh clavicular fractures. Experience with 60 operations. Unfallchirurgie. 14(1):26-37

27. Postacchini F, Gumina S, De Santis P et al (2002) Epidemiology of clavicle fractures. J Shoulder Elbow Surg 11:452-456

28. Potter JM, Jones C, Wild LM, Schemitsch EH, McKee MD (2007) Does delay matter? The restoration of objectively measured shoulder strength and patient-oriented outcome after immediate fixation versus delayed reconstruction of displaced midshaft fractures of the clavicle. J Shoulder Elbow Surg. 16(5):514-518

29. Rabe SB, Oliver GD (2011) Clavicular fracture in a collegiate football player: a case report of rapid return to play. J Athl Train. 46(1):107-111

30. Rowe CR (1968) An atlas of anatomy and treatment of midclavicular fractures. Clin Orthop Relat Res. 58:29-42

31. Russo R, Visconti V, Lorini S, Lombardi LV (2007) Displaced comminuted midshaft clavicle fractures: use of Mennen plate fixation system. J Trauma 63(4):951-954

32. Shen WJ, Liu TJ, Shen YS (1999) Plate fixation of fresh displaced midshaft clavicle fractures. Injury. 30(7):497-500

33. Shen JW, Tong PJ, Qu HB (2008) A three-dimensional reconstruction plate for displaced midshaft fractures of the clavicle. J Bone Joint Surg Br 90(11):1495-1498

34. Smekal V, Oberladstaetter J, Struve P et al (2009) Shaft fractures of the clavicle: current concepts. Arch Orthop Trauma Surg 129:807-815. doi:10.1007/s00402-008-0775-7

35. Thyagarajan DS, Day M, Dent C, Williams R, Evans R (2009) Treatment of mid-shaftclavicle fractures: a comparative study. Int J Shoulder Surg. 3(2):23-27

36. Vanbeek C, Boselli KJ, Cadet ER, Ahmad CS, Levine WN (2011) Precontoured plating of clavicle fractures: decreased hardware-related complications? Clin Orthop Relat Res 469(12):3337-3343

37. Verborgt O, Pittoors K, Van Glabbeek F, Declercq G, Nuyts R, Somville J (2005) Plate fixation of middle-third fractures of the clavicle in the semi-professional athlete. Acta Orthop Belg. 71(1):17-21

38. Wang K, Dowrick A, Choi J, Rahim R, Edwards E (2010) Postoperative numbness and patient satisfaction following plate fixation of clavicular fractures. Injury. 41(7):939-942

39. Zlowodzki M, Zelle BA, Cole PA et al (2005) Treatment of acute midshaft clavicle fractures: systematic review of 2144 fractures: on behalf of the Evidence-Based Orthopaedic Trauma Working Group. J Orthop Trauma 19:504-507 